"The effects of future climate change shocks on macroeconomic aggregates via agricultural production in Tunisia: A dynamic general equilibrium analysis"

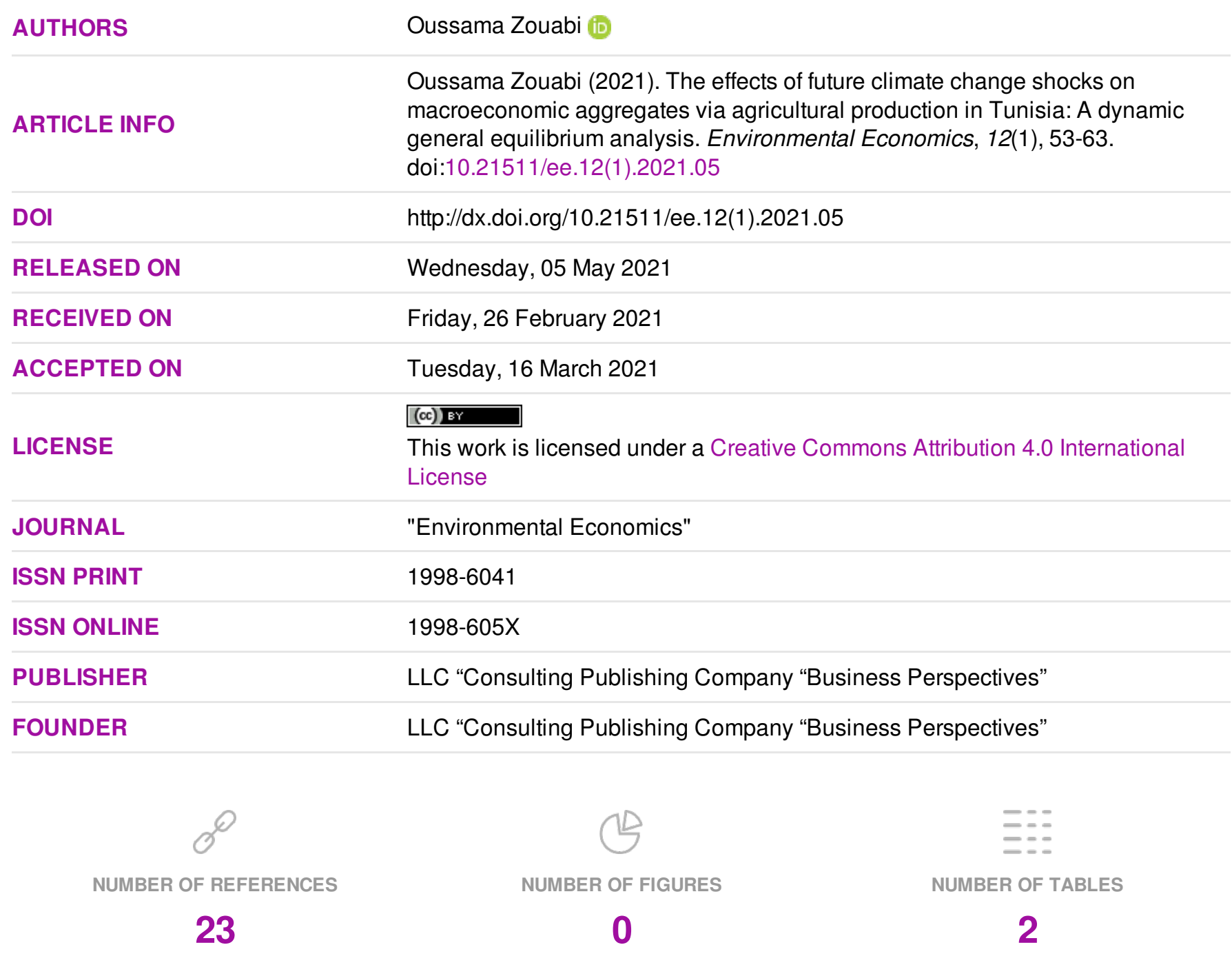

(C) The author(s) 2022. This publication is an open access article. 


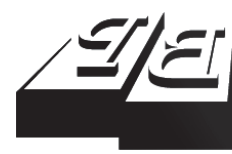

BUSINESS PERSPECTIVES

(O)

LLC "CPC "Business Perspectives" Hryhorii Skovoroda lane, 10, Sumy, 40022, Ukraine www.businessperspectives.org

Received on: $26^{\text {th }}$ of February, 2021 Accepted on: $16^{\text {th }}$ of April, 2021 Published on: $5^{\text {th }}$ of May, 2021

๑) Oussama Zouabi, 2021

Oussama Zouabi, Dr., Faculty of Economics and Management \& LAPE, Economics Department, University of Tunis El Manar, Tunisia; Faculty of Economics and Management \& LEAD, University of Toulon, France.
This is an Open Access article distributed under the terms of the Creative Commons Attribution 4.0 International license, which permits unrestricted re-use, distribution, and reproduction in any medium, provided the original work is properly cited.

Conflict of interest statement: Author(s) reported no conflict of interest

\section{THE EFFECTS OF FUTURE CLIMATE CHANGE SHOCKS ON MACROECONOMIC AGGREGATES VIA AGRICULTURAL PRODUCTION IN TUNISIA: A DYNAMIC GENERAL EQUILIBRIUM ANALYSIS}

\begin{abstract}
This study aims to analyze the direct and indirect impact of future climate changes on agricultural production and macroeconomic aggregates. A dynamic general equilibrium model of the Tunisian economy has been developed, which takes into account the effects of future climate shocks from 2020 to 2050 to assess the impact of future climate change on agricultural production and macroeconomic aggregates. The model is used to simulate various scenarios.

The results of the climate shock simulations clearly show that long-term citrus fruits production is showing remarkable declines in the most citrus-producing governorates following a significant drop in water level in dams and level of groundwater table. In turn, cereals are the plants most affected by the long-term reduction in rainfall. As for the olive production, it would show a decline reaching $-1.263 \%$ between 2020 and 2024 in the level of its production following reduction in rainfall. From a macroeconomic point of view, climate change will result in the short- and long-term in a deterioration of certain quantities, notably household consumption, entrepreneurial investment, and the unemployment rate, which decreases by $-0.139 \%$ between 2031 and 2040. These results underline the need for a long-term agricultural policy to reduce or limit the economic and social consequences of climate change and support economic development.
\end{abstract}

\section{Keywords \\ climatic change, agricultural sector, economic growth, DGE}

\section{JEL Classification $\quad$ Q54, O13, F43, D58}

\section{INTRODUCTION}

Climate change is one of the main concerns from the 21st century; it has large effects on economic growth and the well-being of the population. In Tunisia, the agricultural sector plays an important role in economic and social development influencing the level of employment and the share of its value added in the GDP. Despite its economic importance, the agricultural sector remains particularly sensitive to regional climatic hazards.

The direct and indirect effect of climate change on agricultural production cannot be generalized. The impacts of this phenomenon vary from one governorate to another. Most studies raise the question of sustainable agricultural production facing long-term climatic hazards.

This paper aims to measure the impact of climate change shocks on a series of macroeconomic variables (notably economic growth) through agricultural production. The methodology of the study is 
therefore based on a dynamic and multisectoral general equilibrium model, which integrates the results of an econometric analysis of the climate impact on agricultural productivity and the forecasts of future climate shocks until 2030.

This work tries to remedy the absence of a model, which links the following three factors: climate, agricultural production, and economic growth. Indeed, it was found that all studies in this area use partial models to assess the effect of the climate shock either on agriculture, or on economic growth (Molua, 2006; Deressa, 2007; Ginnakopoulous et al., 2005; Kumar \& Parikh, 2001; Weber \& Hauer, 2003).

To achieve this objective, a dynamic multisectoral general equilibrium model is applied for Tunisia. This model takes into account the reaction over time of the various climate shocks and thus apprehends the economy as a complete system. Therefore, it provides an analysis to grasp the relationship between agriculture and macroeconomic aggregates via temperature, precipitation, dam water level and groundwater level, which are the main channels of shock transmission in this model.

As the second step, the study extends the static analysis used by most studies dealing with the general equilibrium model to quantify the impact of climate change on agricultural production and economic growth (Bosello \& Zhang, 2005). Dynamic analysis makes it possible to analyze the dynamic relationships between the different variables of the model, on the one hand, and to simulate and forecast the economic conditions following climate shocks, on the other hand.

The academic novelty of this paper is justified not only by the use of an original and complete construction of the social accounting matrix and the dynamic general equilibrium model, but also by taking into account the time horizon, which reflects the continuous impact of different shocks while understanding the economy as a complete system.

Consequently, it provides an analysis that makes it possible to understand the link between agriculture and other sectors of the economy via the temperature, precipitation, water level in dams, and the water table, which constitute the main channels of shock transmission in the model.

This paper develops the first general equilibrium tests in environmental economics, which consider the impact of climate change on agricultural production and economic growth in Tunisia. To this end, the paper is interested in the dynamic modeling of computable general equilibrium to capture the direct and indirect impact of climatic variations on agricultural production.

Similarly, the dynamic general equilibrium model allows grasping the effects of future climate shocks on a series of macroeconomic variables via the agricultural production of irrigated and non-irrigated plants. This model can enrich the empirical literature, on the one hand, and study the impact of previous climatic variations and by understanding the future shocks of climatic hazards on agricultural production, on the other hand.

The rest of the paper is organized as follows. The first section presents a review of the empirical literature. The second section is devoted to the theoretical presentation of the equations of the dynamic general equilibrium model and describes the empirical analysis of the model composed of the social accounting matrix of Tunisia. The third section presents and analyzes simulations and results, and the last section concludes the paper. 


\section{LITERATURE REVIEW}

The effects of climate change on agriculture have been developed in several theoretical works, most of which have been applied to developing countries (Mendeldhon et al., 1994; Mendelsohn \& Dinar, 1999; Kumar \& Parikh, 2001; Deressa, 2007). These effects were evaluated according to two approaches: one in terms of partial equilibrium and another in terms of general equilibrium.

Indeed, the analysis according to the partial equilibrium model takes into account part of the global economy, while the general equilibrium model considers the economy as a complete system and thus provides an analysis allowing to grasp the link between agriculture and other sectors of the economy.

The issue of climate change impact on agriculture has been discussed in the literature applying three different models: simulation models, production function models, and Ricardian models.

Simulation models are based on controlled experiments where crops are planted in the field or in the laboratory. In the latter case, different types of climate and different levels of carbon dioxide are simulated to estimate the responses and yields of specific crops under certain climate conditions (Reilly et al., 2003). However, these models do not take into account the adaptation of farmers to climate change (Mendelsohn \& Dinar, 1999).

As for the analysis of agricultural production that is called agricultural production economics models in the area, they combine harvest simulation models, with an analysis of the land management decision and capture changes in agricultural resources and climate conditions (Bardhan, 1975; Darwin et al., 1995; Fischer, \& Sun, 2001).

The agro-economic analysis classifies the existing land by agro-ecological zones, which differ according to the length of the cultivable period and the climate conditions. The length of the cultivable period is defined by temperature, precipitation, and soil characteristics. Indeed, the modeling of harvesting areas and environmental procedures makes it possible to identify the environmental limits under various levels of inputs such as fertilizers, labor, and various management decisions. It also provides optimal assessments of the yields of agronomic crops per unit of land.

Finally, Ricardo's model ${ }^{1}$ is widely used in empirical studies as it quantifies the impact of climate change on agricultural production. This model, launched by Mendeldhon et al. (1994), tried to capture the influence of economic, climatic, and environmental factors on the value of the agricultural area. The principle of the Ricardian approach is that the land value is correlated with climate, in particular temperature and precipitation (Mendelsohn \& Dinar, 1999; Sanghi et al., 1998). This approach is based on the assumption of market efficiency and therefore on the fact that the value of agricultural land reflects the present value of farmers' future income from the most productive use of land (Mendelsohn et al., 1999).

Although partial equilibrium models show some efficiency combining agricultural and climatic variables, which is aimed at improving the estimation of the impact of the latter on the former, they also show the absence of a model linking simultaneously the following three factors: climate, agricultural production, and economic growth. Indeed, most studies in this area use partial models to study either the effect of the climate shock on agriculture, or the impact of the climate shock on economic growth (Molua, 2006; Deressa, 2007; Ginnakopoulous et al., 2005; Kumar \& Parikh, 2001; Weber \& Hauer, 2003).

Besides the insufficiency of partial equilibrium models, there have been no studies explaining the effect of climate change on economic growth through agriculture using a general equilibrium model dynamic, case study Tunisia. The only exception is the World Bank (2012), which concluded that this approach allows dealing with long-term climate shocks. However, the results obtained remain to be taken with caution. Indeed, this study does not make a distinction between seasons insofar, as only annual variables are considered. Moreover, no distinction between the nature of plants or their water need, and even their dependence on the availability of water, is made.

1 David Ricardo observed that the value of the land reflects its profitability in a perfectly competitive market. 


\section{METHODOLOGY}

\subsection{Presentation of the model}

In this section, the study presents the dynamic computable general equilibrium model. The structure of the dynamic model is inspired by the work of Marouani and Robalino (2012). Unlike the base model, which mainly deals with the issue of employment and mobility, this model aims to understand the direct and indirect effects of climate change on the Tunisian economy through the agricultural sector.

For each branch, the output is a Leontief function of added value and intermediate consumption. Likewise, the intermediate consumption of each sector is a Leontief function of the intermediate consumption of each type of product $i$ of sector $j$. Besides, added value is a function with constant elasticity (CES) of three production factors: capital and highly qualified labor, moderately skilled labor, unskilled labor in branch $\mathrm{j}$.

The production is a function with constant elasticity of substitution (CES) with three factors including a composite, and it is written as follows:

$$
\begin{aligned}
& Y_{i}=A_{1}\left[\alpha_{K H S} K H S_{i}^{\frac{\delta 1-1}{\delta 1}}+\right. \\
& \left.+\alpha_{H S} M S_{i}^{\frac{\delta 1-1}{\delta 1}}+\alpha_{L S} L S_{i}^{\frac{\delta 1-1}{\delta 1}}\right]^{\frac{\delta 1}{\delta 1-1}}, \\
& K H S_{i}=A_{1}^{(\delta 1-1)} Y_{i}\left(\alpha_{K H S} \frac{P V A_{i}}{P K H S_{i}}\right)^{\delta 1}, \\
& M S_{i}=A_{1}^{(\delta 1-1)} Y_{i}\left(\alpha_{H S L} \frac{P V A_{i}}{P M S_{i}}\right)^{\delta 1}, \\
& L S_{i}=A_{1}^{(\delta 1-1)} Y_{i}\left(\alpha_{L S L} \frac{P V A_{i}}{P L S_{i}}\right)^{\delta 1}, \\
& K H S_{i}=A_{2}\left[\alpha_{K} K_{i}^{\frac{\delta 2-1}{\delta 2}}+\alpha_{H S L} L D_{i, H S L}^{\frac{\delta 2-1}{\delta 2}}\right]^{\frac{\delta 2}{\delta 2-1}}, \\
& L D_{i, f}=\left[\sum_{a} a(a) L D A_{i, f, a}^{\frac{\delta 3-1}{\delta 3}}\right]^{\frac{\delta 3}{\delta 3-1}},
\end{aligned}
$$

where $Y_{i}$ - Production by sector, KHS - Capital and highly skilled workforce, $M S$ - Moderately qualified work, LS - Unskilled work, PVA - Valueadded price by sector, PKHS - Price of the capital aggregate and highly qualified workforce, $P M S$ Price of moderately qualified labor, PLS - Price of unskilled labor, $K$ - Capital, $L D_{i, f, a}$ - Labor demand by sector and by age, Scale parameter, $\delta_{1}-$ Elasticity of substitution, $\alpha_{K H S}, \alpha_{H S}, \alpha_{L S}, \alpha_{H S L}, \alpha_{K}-$ Proportion parameters.

The market equilibrium is written as follows:

$$
Y_{i}=\sum_{i} C_{i, j, t}+C G_{i, t}+I N V_{i, t}+D L_{i, t}+S K_{i, t},
$$

where $C_{i, j, t}$ - Household consumption, $C G_{i, t}$ - Public consumption, $I N V_{i, t}$ - Demand of Investment, $D I_{i, t}$ - Demand for intermediate Good, $S K_{i, t}$ - Changes in the stock of capital

The equilibrium on the labor market is represented as follows -

$$
L S=\sum L D_{i, t}
$$

where $L S$ - Labor Supply, LDi - Labor Demand.

The equilibrium on the capital market is given by the formula -

$K S=\sum K D_{i, t}$,

where $K S$ - Supply of Capital, $K D_{i, t}$ - Demand for Capital.

The equilibrium of investment and savings is given by -

$$
I T=S M+S E+S G+C A B,
$$

where IT - Total Investment, $S M$ - Households savings, $S E$ - Savings of Firms, $S G$ - Government Savings, $C A B$ - Balance of trade.

\subsection{Tunisia's social accounting matrix}

To calibrate the model, it is necessary to move from the theoretical model developed in the computable dynamic model. To do this, it is essential to create a database for a particular year to estimate the value of endogenous and exogenous variables, as well as cer- 
tain parameters of the theoretical model developed in the previous section. The main idea is to use the social accounting matrix as the empirical basis of the model.

The social accounting matrix is part of the large family of economic tables. It has a dual purpose: to provide a coherent presentation of transactions taking place across the country or regions, on the one hand, and on the other hand, to provide economic policy decision-makers with an accounting base and an analytical framework that can facilitate their choices (Decaluwé et al., 1986). It can be presented as a square table that simulates change in value between the different accounts of the economy. In general, the accounts of the social accounting matrix are the branch account, the property account, the factors of production account, and the accounts of the agents.

The Tunisian social accounting matrix for 2016 is constructed as follows: 3 accounts of agents (households, state, and rest of the world), 3 factors of production (labor, capital, and land) and 82 production accounts including 14 agricultural, 32 industrial and 31 service ones.

\subsection{Calibration procedures of a dynamic model}

The first step in the process was to divide the agricultural sector into 14 sub-branches to identify the links between the agricultural sector and other sectors of the economy, as well as interconnections between different entities of the agricultural sector in Tunisia. This step is essential and has double advantage. On the one hand, it helps to identify the future effect of a climate shock on agricultural production in a disaggregated and global way, and to understand how this effect is spreading to other sectors of the economy, on the other hand.

The second step is to predict the evolution of the various climatic variables. This forecast is based on disaggregated daily data covering the period from 2020 to 2050. It calculates the overall productivity of cereal plants, olive, and citrus, and integrates the Total Factor Productivity (TFP) into the dynamic general equilibrium model.

However, modeling requires a calculation how each plant responses within the TFP to future climate shocks. It is necessary to determine the new values of the climate variables after integrating the smooth shocks for each variable. Before calculating the TFP of each production, it is essential to calculate the elasticities of each variable integrated into the model for each plant, which then allows us to calculate the growth rates of the TFP and integrate it into the computable general equilibrium model.

The purpose of this section is to incorporate the results of the partial model into the dynamic general equilibrium model, which focuses on forecasting future temperature and precipitation shocks to economic growth through agricultural production until 2050.

The social accounting matrix (SAM) presented in the previous section shows the empirical basis for calibrating the model. It determines endogenous and exogenous variables, as well as several parameters. Most of the variables presented are determined from the SAM while others are calculated based on the available data. However, some parameters cannot be calibrated directly via the SAM.

To overcome this difficulty, three solutions are possible. Either the elasticity values are unilaterally and randomly specified at reasonable levels, or elasticities used in other studies that have dealt with the same problem are incorporated into the model. Additionally, these parameters may be estimated econometrically.

In this connection, due to the scarcity of empirical works that focused on the direct and indirect impact of climate change on agricultural production of irrigated and unirrigated plants in Tunisia, the study estimated the overall productivity function of each plant through the ordinary least square method (OLS). This method relates the effect of temperature and precipitation on non-irrigated plants (cereals and olives) and the impact of precipitation and the average temperature on irrigated plants (vegetables, citrus fruits, potatoes, and palm trees) via water level in dams and the groundwater level.

\subsection{Simulation}

The various simulations used in this paper were built based on the results of the report of the German society for international cooperation GIZ 
on the adaptation of Tunisian agriculture and ecosystems to Climate Change (2012) and Clim Var $(2015)^{2}$. The climate projections for this study were based on the results of the HadCM3 model from 2015 to 2050. The results are presented from the regional scenarios compared for the 1961-1990 reference period. Several shocks are simulated to analyze the effects of climate change on agricultural production and a range of macro-economic and sectoral variables.

Simulation 1 (SIM 1): The first scenario concerns the effects of the future climate shock on a series of short- and long-term macroeconomic magnitudes through the production of cereals, olives, and citrus fruits. The next four shocks were performed simultaneously. The first simulated shock consists of an increase in the average temperature of $0.3^{\circ} \mathrm{C}$ and a significant decrease in rainfall of $4.6 \%$ from 2020 to 2030.

In this scenario, the water stored in the dams decreases of $11 \%$, and the water table decreases of $60 \%$ during the same period.

Simulation 2 (SIM 2): The second scenario is to simulate the same variables used in the first scenario from 2031 to 2050. In the first phase, the simulated climate shock is an increase in the average temperature of $1.75^{\circ} \mathrm{C}$, and the variability of precipitation that decreases compared to the period 2020-2030 and reaches $9 \%$. In the second stage, the simulation assumes a sharp decrease in the water table of $65 \%$ and a decrease of the dam water of $17 \%$ from 2031 to 2050 . The results of these shocks are compared with those of the first scenario.

\section{RESULTS AND DISCUSSION}

\subsection{Results at the sector level}

The main finding from the analysis of Table 1 is that shocks have contrasting effects on agricultural production compared to its baseline (2016).

Firstly, the study noted that a decrease in agricultural production is estimated from 2020 to 2030 for SIM1, contrary to the SIM2 scenario, where the shock is slightly increasing from 2031 to 2040, and then resulting in a slight decrease between 2041-2050.

Thus, in the same way, agricultural production responds to a decrease in precipitation, dam water level, and level of groundwater table from 2041 until the terminal period, reaching $3.559 \%$. The explanation for the decline in agricultural production in the short and long term lies in the decrease in the production of certain plants, specifically cereals, olives, and citrus fruits. These plants account for a large share of agricultural production in Tunisia, and are directly or indirectly affected by climate change.

Concerning the evolution of irrigated and unseeded plants, it should be noted that both simulations lead to a decline in agricultural production, which is much greater in the second scenario than in the first. The expected effect of the shock is a decrease in olive and cereal production compared to the baseline scenario, confirmed by Table 1, which shows a decrease in olive production reaching $1.263 \%$ and $1.921 \%$, respectively, during the period 2020-2024 and 2041-2050. Nevertheless, there was a slight increase in cereal production from 2031 to 2040, followed by a sharp decrease reaching $-6.07 \%$ from 2041 to 2050.

A more detailed analysis of SIM1 and SIM2 and their impact on the production of irrigated plants shows that citrus production is mostly affected in both scenarios. The various climatic shocks have the effect of a steady decline in citrus production from its reference level until 2030 when it reaches $-4.144 \%$, which can be explained by the sharp decrease in groundwater by $11 \%$.

Besides, the results of the various simulations confirm the decline in the production of irrigated plants, which is caused by a decrease in the production of vegetables reaching $-0.341 \%$ and potatoes of $-0.460 \%$. In addition, the production of palm trees, which is one of the main exports of the Tunisian economy, is suffering a long-term decline reaching $-1.08 \%$.

2 ClimVar project (MedPartnership) "Integration of climate variability and change in national strategies" national report October 2015. 
Table 1. Sector results

\begin{tabular}{|c|c|c|c|c|}
\hline \multirow{2}{*}{$\begin{array}{c}\text { Simulation } \\
\text { Period }\end{array}$} & \multicolumn{2}{|c|}{ SIM 1} & \multicolumn{2}{|c|}{ SIM2 } \\
\hline & $2020 / 2024$ & $2025 / 2030$ & $2031 / 2040$ & $2041 / 2050$ \\
\hline Cereal & -1.34 & -1.59 & 0.958 & -6.07 \\
\hline Vegetables & -0.278 & -0.319 & 0.485 & -0.291 \\
\hline Fruits & -0.556 & -0.653 & -0.145 & -0.513 \\
\hline Potato & -0.458 & -0.556 & -0.485 & -0.342 \\
\hline Citrus & -1.852 & -4.144 & -2.485 & -5.122 \\
\hline Almond & -0.278 & -0.190 & -0.970 & -0.019 \\
\hline Olive & -1.263 & -0.095 & -0.920 & -1.921 \\
\hline Dates & -1.455 & -1.600 & -0.161 & -1.110 \\
\hline Rice & -0.477 & -0.834 & -0.485 & -0.417 \\
\hline Arboriculture & -0.570 & -0.736 & -3.880 & 3.040 \\
\hline Other Agriculture & -1.263 & 2.080 & 0.956 & -0.403 \\
\hline Livestock & -1.350 & -0.714 & 0.474 & -0.980 \\
\hline Agricultural sector & -0.788 & -0.615 & 0.502 & -3.559 \\
\hline Agrifood & -1.263 & -0.95 & 0.145 & -0.848 \\
\hline
\end{tabular}

Therefore, based on logical reasoning and in accordance with the intuitions, a decline in production in the agricultural sector, which is the main item of intermediate consumption in the agrifood sector, will have a downward effect on the industrial sector through the agrifood industry. To confirm this result, it is necessary to observe the evolution of agrifood production.

This observation clearly shows that any decrease in agricultural production due to future climate shocks will have immediate and drastic consequences for agrifood production. The results of the simulations show that at first agrifood production decreases in the short term, and increase slightly from 2031 to 2040 due to a slight boost in agricultural production following a sharp boost in other agricultural activities, and then shows a downward rate until the final period, reaching $-0.848 \%$.

In conclusion, the results of climate shock simulations proves that climate change negatively affects agricultural production in the short and long term due to the decrease in the production of dependent irrigated and non-irrigated plants both directly or indirectly and growth of climate variables.

This decline in agricultural production, in turn, leads to a decrease in the agrifood industry production. Such a fall is likely to affect the level of investment it is subject to, the level of the population employed by this sector of activity, and by a chain effect, the level of consumption.

\subsection{Overall effect on the economy}

The evolution of Tunisia's main economic indicators for simulated shocks is shown in Table 2.

As the results obtained with the two simulations illustrate, both shocks lead to a much larger medium- and short-term decline in investment during the first shock, with a decrease of $-0.451 \%$ from 2025 to 2030 . On the other hand, from 2031 to 2040, investment increased by $0.18 \%$, which can be explained by the decline in energy subsidies, due to the contraction of agricultural production, as agriculture is a major consumer of subsidized diesel. This results in a slight decrease in the investment to $-0.048 \%$ from 2041 to 2050, which negatively effects agricultural production.

Similarly, according to Table 2, changes in the labor demand are affected by the decrease in total investment in SIM1 and SIM2 scenarios. There was a decrease in labor demand to $-0.171 \%$ and $-0.227 \%$ respectively in the medium and long term.

In the medium term and from 2025 to 2030 , total investment decreases relative to the reference period and demand for work decreases. As a result, the unemployment rate is up to $0.145 \%$ over the reference period. Similarly, in the long term, a decrease in the investment to $-0.048 \%$, leads to an increase in the unemployment rate reaching $0.145 \%$ following a decrease in labor demand. 
Table 2. Macroeconomic results

\begin{tabular}{|c|c|c|c|c|}
\hline \multirow{2}{*}{$\begin{array}{c}\text { Simulation } \\
\text { Period }\end{array}$} & \multicolumn{2}{|c|}{ SIM1 } & \multicolumn{2}{|c|}{ SIM2 } \\
\hline & $2020 / 2024$ & $2025 / 2030$ & $2031 / 2040$ & $2041 / 2050$ \\
\hline GDP & -0.485 & -0.515 & 0.278 & -0.812 \\
\hline Public deficit & -0.514 & 0.735 & -0.485 & -0.570 \\
\hline Public debt & -0.161 & -0.417 & -0.145 & -0.122 \\
\hline Total investment & 0.161 & -0.451 & 0.180 & -0.048 \\
\hline Job application & 0.401 & -0.171 & 0.231 & -0.227 \\
\hline Exchange rate & $-0.217 \%$ & $-0.127 \%$ & $-0.103 \%$ & $-0.314 \%$ \\
\hline Total unemployment rate & -0.521 & 0.421 & -0.139 & 0.145 \\
\hline Household consumption & -0.095 & -0.373 & 0.111 & -0.565 \\
\hline
\end{tabular}

Thus, it is clear that upstream climate change is affecting labor demand in the agricultural and agrifood sector, directly through the decline in the level of production in the agricultural sector and indirectly through the decline in investment in agrifood activity, which lead to a decrease in the demand for factors of production. This drop in the level of labor demand, in turn, leads to an increase in the level of the unemployment rate.

Table 2 shows a variation in the level of household consumption with climate shock. Indeed, considering the income of wages and returns of capital from agricultural and agrifood activities, the impact of changes in climate variables will be felt by households through a reduction in their purchasing power.

Between 2025 and 2030, a $-0.373 \%$ decrease in household consumption is recorded in parallel with a decrease in investment to $-0.451 \%$ in SIM1. SIM2 from 2041 to 2050 shows a decrease in consumption reaching $-0.565 \%$ in conjunction with a $-0.048 \%$ decrease in investment.

Besides, a change in the exchange rate of the Tunisian Dinar induces a set of economic effects, due to its impact on the international competitiveness of Tunisian agricultural and agri-food products. That is, it shows a negative impact in terms of exports of agricultural products (olive, dates, citrus), which account for a very large share of Tunisian exports (more than $50 \%$ of total exports), and a positive impact in terms of the cost of imports and debt service.

Given previous results on the impact of climate change factors on both agricultural and agrifood products, on investment and employment, it is clear that climate change has a negative effect on GDP.

\section{CONCLUSION}

The paper analyzed the effect of climate change on agricultural production and macroeconomic aggregates from 2020 to 2050. A dynamic multisectoral general equilibrium model is used, which takes into account the effects of future climate shocks, making the most reliable database.

The main results of the simulations show that the negative impact of climate change on agricultural and agrifood production in Tunisia is due to the drop in precipitation, the rise in temperatures and the drying up of groundwater. The results found in this paper are in line with the expectations and with an economic theory, which is based on the fact that a drop in precipitation, water level in dams and the level of groundwater table cause a decrease in the production of irrigated and non-irrigated plants. Therefore, it negatively affects agricultural production as a whole.

At the sectoral level, the results reveal that the production of irrigated plants is generally reduced. Citrus fruit show the most significant decrease due to a sharp drop of water level in dams and the level of groundwater table. However, a sharp drop in rainfall results in a decrease in olive production in the short and long term, while a decrease in cereal production took place from 2041 to 2050 following a $9 \%$ decrease in rainfall. 
This impact, which arises from the deterioration of certain macroeconomic variables such as household consumption, entrepreneurial investment and the unemployment rate, can be observed in both short and long term. The results also reveal a significant negative impact of climate change on GDP, which is entirely admissible insofar as the macroeconomic variables taken into account constitute the main components of GDP.

To cope with the economic and social consequences of this climate change, a long-term targeted agricultural policy is essential. These economic policies, oriented on the productive potential of the governorates and the nature of the problem, must be well balanced. Otherwise, they could have harmful social consequences. For example, a policy that does not take into account the subsidy of palm producers in the South region, which can lead to collective migration towards neighboring governorates and negatively affect the growth rate in these regions and increase, therefore, the unemployment rate.

Authorities can also resort to other techniques such as selecting crops with the same or higher yields, but with lower water requirements for their growth, or in an extreme case, favoring genetically modified crops (GMOs) to compensate for water scarcity and lack of rainfall, following the example of such countries as China and India.

Finally, the Tunisian Ministry of Agriculture must undertake measures to rationalize the use of water in the governorates most affected by this phenomenon. Besides, the use of modern water desalination techniques can help increase agricultural production, particularly irrigated agriculture.

\section{AUTHOR CONTRIBUTIONS}

Data curation: Oussama Zouabi.

Formal analysis: Oussama Zouabi.

Methodology: Oussama Zouabi.

Resources: Oussama Zouabi.

Validation: Oussama Zouabi.

Writing - original draft: Oussama Zouabi.

Writing - review \& editing: Oussama Zouabi.

\section{REFERENCES}

1. Arndt, C., Farmer, W., Strzepek, K., \& Thurlow, J. (2012). Climate Change, Agriculture and Food Security in Tanzania. Review of Development Economics, 16(3), 378-393. https://doi.org/10.1111/ j.1467-9361.2012.00669.x

2. Bardhan, K. (1973). Size, Productivity, and Returns to Scale: An Analysis of Farm-Level Data in Indian Agriculture. The Journal of Political Economy, 81, 1370-1386. http://dx.doi.org/10.1086/260132

3. Bosello, F., \& Zhang, J. (2005). Assessing Climate Change Impacts: Agriculture (Working Paper No. 94.05). Climate Impacts and Policy Division. Retrieved from https://papers.ssrn.com/sol3/papers.cfm?abstract_id $=771245$
4. Cline, W. R. (1996). The Impact of Global Warming on Agriculture: Comment. American Economic Review, 86(5), 1309-1312. Retrieved from https://www.jstor. org/stable/2118295

5. Cline, W. R. (2007). Global Warming and Agriculture: Impact Estimates by Country. Center for Global Development and Peterson Institute for International Economics, Washington, DC. Retrieved from https://www.cgdev. org/publication/9780881324037global-warming-and-agricultureimpact-estimates-country

6. Darwin, R., Marinos, T., Lewandrowski, J., \& Raneses, A. (1995). World Agriculture and Climate Change: Economic
Adaptations Agricultural Economic (An Economic Research Service Report No. 703). United States Department of Agriculture, Washington, D.C. http://dx.doi. org/10.22004/ag.econ.33933

7. Decaluwé, B., Martens, A., \& Monette, M. (1986). Comment construire un modèle calculable d'équilibre général? Une illustration. L'Actualité économique, 62(3), 442-473. https://doi. org/10.7202/601381ar

8. Deressa, T. D. (2007). Measuring the economic impact of climate change on Ethiopian agriculture: A Ricardian approach (Policy Research Working Paper No. 4342). World Bank. Retrieved 
from http://hdl.handle. net/10986/7290

9. Elshennawy, A., Robinson, S., \& Willenbockel, D. (2013). Climate Change and Economic Growth: An Intertemporal General Equilibrium Analysis. Economic Modelling, 52(B), 681-689. https://doi.org/10.1016/j.econmod.2015.10.008

10. Fischer, G., \& Sun, L. (2001). Model-based analysis of future land-use development in China. Agriculture, Ecosystems and Environment, 85(1-3), 163-176. https://doi.org/10.1016/S01678809(01)00182-7

11. Gebreegziabher, Z., Stage, J., Mekonnen, A., \& Atlaw, A. (2011). Climate Change and the Ethiopian Economy: A Computable General Equilibrium Analysis (Discussion Paper Series No. EfD DP 11-09). Environment for Development. https://doi.org/10.1017/ S1355770X15000170

12. Kumar, K. S. K., \& Parikh, J. (2001). Indian Agriculture and Climate Sensitivity. Global Environmental Change, 11(2),147154. https://doi.org/10.1016/ S0959-3780(01)00004-8

13. Marouani, M. A., \& Robalino, D. A. (2012). Assessing interactions among education, social insurance and labor market policies in Morocco. Applied Economics, 44(24), 3149-3167. https://doi.org/ $10.1080 / 00036846.2011 .570721$
14. Mendeldhon, R., Nordhaus, W., \& Shaw, D. (1994). The impact of global warming on agriculture: A Ricardian analysis. American Economic Review, 84(4), 753771. Retrieved from https://ideas. repec.org/a/aea/aecrev/v84y1994i4p753-71.html

15. Mendelsohn, R., \& Dinar, A. (1999). Climate Change, Agriculture, and Developing Countries: Does Adaptation Matter? World Bank Research Observer, 14(2), 277-293. https:// www.jstor.org/stable/3986368

16. Molua, E. (2006). Turning up the heat on African agriculture: The impact of climate change on Cameroon's agriculture. The African Journal of Agricultural and Research Economics, 2(1), 45-65. https://doi.org/10.22004/ ag.econ.56967

17. Reilly, J., Tubiello, F., McCarl, B., Abler, D., Darwin, R., Fuglie, K., Hollinger, S., Izaurralde, C., Jagtap, S., Jones, J., Learns, L., Ojima, D., Paul, E., Paustian, K., Riha, S., Rosenberg, N., \& Rosenzweig, C. (2003). U.S. agriculture and climate change: New results. Climatic Change, 57, 43-69. https://doi. org/10.1023/A:1022103315424

18. Robinson, S., Willenbockel, D., \& Strzepek, K. (2012). A Dynamic General Equilibrium Analysis of Adaptation to Climate Change in Ethiopia. Review of Development
Economics, 16(3), 489-502. https://doi.org/10.1111/j.14679361.2012.00676.x

19. Sanghi, A., Mendeldhon, R., \& Dinar, A. (1998). The climate sensitivity of Indian agriculture (World Bank Technical Paper No. 402). Washington, DC

20. Singh, B., El Maayar, M., André, P., Bryant, C. R., \& Thouez, J. P. (1998). Impacts of a GhgInduced Climate Change on Crop Yields: Effects of Acceleration in Maturation, Moisture Stress and Optimal Temperature. Climatic Change, 38(1), 51-86. https://doi. org/10.1023/A:1005392517715

21. Wang, J., Mendelsohn, R., Dinar, A., Huang, J., Rozelle, S., \& Zhang, L. (2008). The Impact of Climate Change on China's Agriculture. Agricultural Economics, 40(3), 323-337. https://doi.org/10.1111/ j.1574-0862.2009.00379.x

22. Weber, M., \& Hauer, G. (2003). A Regional Analysis of Climate Change Impacts on Canadian Agriculture. Canadian Public Policy, 29(2), 163-180. https://doi. org/10.2307/3552453

23. Zhai, F., Tun, L., \& Byambadorj, E. (2009). A General Equilibrium Analysis of the Impact of Climate Change on Agriculture in the People's Republic of China. Asian Development Review, 26(1), 206225. Retrieved from http://hdl. handle.net/11540/1680 


\section{APPENDIX A}

\section{National Budget Resources}

$$
\begin{aligned}
& S G=Y G-G V A L-T R S F-\sum_{i}\left(1-i s u b_{i}\right) \cdot I N V_{i} \cdot P I N V_{i}-\operatorname{shrginv} \cdot \sum_{i} I N V_{i} \cdot P I N V_{i} \\
& -i r g f \cdot G F D E B T-i r i \cdot G I D E B T,
\end{aligned}
$$

where $S G$ - National savings, $Y G$ - government income, GVAL - government spending, INV Investment, PINV - Investment price by sector, GFDEBT - Public External debt, GIDEBT - Domestic public debt, isub_i - Investment subsidy by sector, Shrginv - Share of public investment, Irgf - Interest rate on external debt Iri - Interest rate on domestic debt.

\section{Investment}

$$
I N V_{i}=M U \cdot K D_{i} \cdot e^{\frac{\beta R K_{i}}{P K_{i}}},
$$

where $M U$ - Adjustment variable, $K D$ - Capital demand, $R K_{i}$ - Principal repayment, $P K_{i}$ - Cost of Capital.

\section{Exports}

They are given by the following formulas:

$$
X_{x, t}=A_{x}\left[\alpha_{x}\left(Q X_{x, t}\right)^{\rho x}+\left(1-\alpha_{x}\right)\left(Q D_{x, t}\right)^{\rho x}\right]^{1 / \rho x},
$$

where $X_{x, t}$ - The quantity of final good, $Q X_{x, t}$ - Quantity of good $i$ exported, $Q D_{x, t}$ - Quantity of goods supplied on the local market, $\alpha_{x}$ - Proportion parameter, $A_{x}$ - Parameter of scale, Elasticity of substitution that equals $\left(1+\sigma_{\mathrm{i}}\right) / \sigma_{\mathrm{i}}$

Profit maximization gives us the relationship between the quantity exported and the number of goods supplied on the domestic market. The result is:

$$
Q X_{x, t}=\left[a_{x} /\left(1-a_{x}\right) P_{w, x} / P_{l, x}\right]^{\sigma x} Q D_{x, t},
$$

where $P_{w, x}$ and $P_{l, x}$ represent respectively the international and local price of the good $i$.

\section{Imports}

They are given by the following formulas:

$$
Q_{m, t}=A_{m}\left[\alpha_{m}\left(Q M_{m, t}\right)^{\rho m}+\left(1-\alpha_{m}\right)\left(D L_{m, t}\right)^{\rho m}\right]^{1 / \rho m},
$$

where $Q_{m, t}$ - Consumption of composite products, $Q M_{m, t}$ - Quantity of imported good i, $D L_{m, t}$ - Quantity of good $i$ supplied on the domestic market, $\alpha_{m}$ - Proportion parameter, $A_{m}$ - Constant of the substitution function, $\rho m$ - Elasticity of substitution that equals $\left(1+\sigma_{i}\right) / \sigma_{i}$, Profit maximization shows the relationship between the imported quantity and the quantity of goods, supplied on the domestic market. The result is:

$$
D L_{m, t}=\left[a_{m} /\left(1-a_{m}\right) P_{m, x} / P_{l, t}\right]^{\sigma m} Q \cdot M_{m, t},
$$

where $P_{m, x}$ and $P_{l, x}$ represent respectively the domestic price and the price of imported good $i$. 